\title{
Does Physical Activity and Sport Practice Lead to a Healthier Lifestyle and Eating Habits in Male Adolescents?
}

\author{
Fonte $\mathrm{ML}^{1}$, Casali $\mathrm{MP}^{2}$, Roggi $\mathrm{C}^{1}$, Turconi $\mathrm{G}^{1}$ and Cena $\mathrm{H}^{* 1}$
}

${ }^{1}$ Department of Public Health, University of Pavia, Pavia, Italy

${ }^{2}$ Medical Sport Centre "Medica Sport Minerva", Pavia, Italy

${ }^{*}$ Corresponding author: Cena H, Department of Public Health, Experimental and Forensic Medicine-Unit of Human Nutrition, University of Pavia, Pavia, Italy, Fax: +39 382 987191, Tel: +39 382 987542, E-mail: hcena@unipv.it

Citation: Fonte ML, Casali MP, Roggi C, Turconi G, Cena H (2014) Does Physical Activity and Sport Practice Lead to a Healthier Lifestyle and Eating Habits in Male Adolescents? J Nutr Health Sci 1(1): 103. doi: 10.15744/2393-9060.1.103

Received Date: February 23, 2014 Accepted Date: May 16, 2014 Published Date: May 20, 2014

\begin{abstract}
Background: The prevalence of childhood obesity has been increasing rapidly and there is general consensus that good nutritional practices and physical activity should be encouraged as early as possible in life. The aim of this study was to describe and to compare the current lifestyle and dietary pattern of normal weight (NW) and overweight + obese (OW+OB) male adolescents who are physically active.

Methods: This observational and retrospective study was based on clinical records analysis of male adolescents aged 11-18 years who had undergone a medical evaluation at a Medical Sport Centre (Pavia, Italy) during 2009, and had filled in a self-administered life style questionnaire.

Results: The results showed that out of 1423 clinical records $23.0 \%$ of subjects were OW, $5.4 \%$ OB and $71.6 \%$ NW. We invited all the overweight and obese subjects to participate in the study, 308 of them (75.8\%) agreed. Then we randomly enrolled an equivalent number of NW participants $(\mathrm{n}=308)$ in the medical evaluation at the sports center with similar characteristics as for socio-economic status, physical activity and age for a whole sample of 616 subjects. We handled them a validated lifestyle questionnaire. The questionnaire analysis was used to compare $\mathrm{OW}+\mathrm{OB}$ and NW participants, as far as eating habits, sedentary activities and time spent in sports. All the subjects frequently skipped breakfast, did not consume fruit and vegetables daily and had a high soft drinks intake. Inverse correlations were found between weight and physical activity $(\mathrm{p}=0.01$ ). Sedentary activities were preferred by about $25 \%$ and $66 \%$ of the NW and $\mathrm{OW}+\mathrm{OB}$ groups respectively. The percentage of smokers was similar within the two groups (14\%).

Conclusions: Adolescents eating habits are incorrect, despite BMI and sports practice. Sports practice seems contributing to lower spare time physical inactivity, but does not improve eating habits. Public health interventions should focus on the reinforcement of leisure time physical activity, besides nutrition education and behavioral education programs in order to prevent obesity in the adulthood.
\end{abstract}

Keywords: Adolescents overweight; Obesity; Sedentarianism; Physical activity; Food habits

List of Abbreviations: NW-Normal weight subjects; OW+OB-Overweight and obese subjects; BMI- Body Mass Index

\section{Introduction}

The prevalence of childhood obesity has been increasing rapidly since 1980s [1]. Currently 10\% of children worldwide are either overweight or obese [2]. Adolescents obesity frequently persists into adulthood, with up to $80 \%$ of obese children expected to become obese adults [3]. There is general consensus that good nutritional practices and physical activity should be encouraged as early as possible in life, and that parent's knowledge, attitudes and behavior are important in creating role models [4]. Indeed, people are likely to maintain the eating habits developed during childhood and adolescence into adulthood. A balanced diet helps to reduce the incidence of overweight and obesity. A high-quality diet promotes proper growth and development, and contributes to the young person's ability to learn[5]. Major inadequacies in the food consumption patterns of adolescents have been identified over the past decades: low consumption of fruits and vegetables, frequent high fat/ high sugar snacking [6-8], high intake of sugar sweetened beverages [9-11]. Another common finding in adolescents is frequent skipping of meals, particularly breakfast [6]. The Health Behaviour in School-aged Children survey[12] showed that only 30\% of boys and 37\% of girls aged 13-15 years eat fruit every day. Vegetable consumption shows a similar pattern. Another condition, which is linked to obesity, is physical inactivity. It is alarming that children have adopted many of the deleterious behavior and lifestyle patterns of the adult population, and are becoming increasingly sedentary and overweight [13]. 
There are a number of severe health-related consequences of this habit. In a report from the National Institutes of Health on the identification and treatment of overweight and obesity, physical inactivity was identified as the major risk for obesity, cardiovascular disease and diabetes [14]. Physical inactivity and excess weight are reported to increase risk of cancer (esophagus, colon, rectum and kidney) [15]. In addition, physical inactivity is a risk factor for skeletal and cardiac muscle atrophy [16]. Weather energy intake or expenditure contributes most to obesity development in childhood is still under investigation. A recent systematical review of the literature on this subject [17], reported that there is no consensus on the main driver of secular trends on weight gain in adolescents and that further research is needed to identify the relative contribution of energy intake and energy expenditure to obesity in the pediatric population [17]. Although many factors such as behavioral, social and environmental ones contribute to the obesity epidemic, the main pathogenic cause is identifiable in an energy imbalance. If this energy imbalance, mainly due to today 'obesogenic' environment, is linked to the children's tendency to consume too much or exercise too little, is not evident. Some authors underline that the energy expenditure decrease accounts for most of the increase in obesity prevalence while others show that rising obesity is primarily the result of consuming more calories [13-21].

The steady rise in life expectancy observed in the modern era is slowly coming to an end and the youth of today, for the first time, might live less healthy and possibly even less longer than their parents [18]. Understanding the relative importance of eating habits and physical activity to weight status among physically active adolescents may contribute to develop interventions and improve policies to prevent and to treat obesity as early as possible. The aim of this study was to describe and to compare the current lifestyle and dietary pattern of a group of normal weight (NW) and overweight +obese (OW+OB) male adolescents who are physically active practicing sports and verify if those who were in the $\mathrm{OW}+\mathrm{OB}$ category had a poorer lifestyle and diet. This convenience sample has been chosen since it was part of another study aimed at assessing body composition in overweight/obese and normal weight, physically active, male adolescents.

\section{Methods}

The study design was retrospective, descriptive and observational. The investigation was conducted on 1423 clinical records of male children and adolescents aged 11-18 years who underwent a medical evaluation at the Sport Medical Centre "Minerva" of Pavia during the year 2009.

The inclusion criteria were: male sex, age between 11 and 18 years, absence of any disease. Age, weight, height, type of sport practiced were drawn from patient's record. The sample consisted of students. They all used to attend 2 hours per week of gymnastics at school, as ministerial curricula provide here in Italy, with no impact on any of the variables considered.

For this study we considered the entire group of the $\mathrm{OW}+\mathrm{OB}$. We invited all the overweight and obese subjects to participate in the study, $75.8 \%$ of them agreed $(n=308)$. We randomly enrolled an equivalent number of NW $(n=308)$ participants in the medical evaluation at the sports center with similar characteristics as for socio-economic status, physical activity and age for a whole sample of 616 subjects.

NW, OW and $\mathrm{OB}$ category has been estimated according to the extended international BMI cut-offs as recently reported by Cole et al [22]. The authors underline that these new cut-offs are virtually identical to the original ones and that prevalence rates based on these are consistent with, and can be compared directly with, rates based on the original cut-offs. The new cut-offs are easy to derive (e.g. BMI 35 for morbid obesity), and they can be expressed as BMI centiles (e.g. boys obesity $=98.9^{\text {th }}$ centile), allowing them to be compared with other BMI references [22].

Hence, we handed and explained a validated self-administered life style and dietary questionnaire, reported in appendix 1 at the end of the manuscript $[20,21]$ to all of the selected subjects during the medical evaluation at the Sport Medical Centre "Minerva" of Pavia. They were invited to fill in the questionnaire and hand it back before the medical evaluation itself. All participants had been informed of the study goals, and the parent or guardian of each participant provided written informed consent.

The study was conducted in accordance with the World Medical Association's Helsinki Declaration for Human Studies and approved by the Ethics Committee of the Faculty of Medicine of the University of Pavia.

\section{Questionnaire}

We used part of an original questionnaire that covers food habits, physical activity and lifestyle, healthy and unhealthy dietary habits and food, self-efficacy, barriers to change, nutrition knowledge, food safety knowledge, food safety and behavior in hygiene practices [20,21]. Three sections of this previously validated questionnaire have been self-administered aiming at investigating food frequency, food behavior and physical activity. Besides a fourth section on smoke habits with 3 questions, was developed and administered.

The first section (Section A: Frequency of Food Consumption) contains 28 questions aimed at investigating daily frequency of consumption of Italian typical foods and beverages such as bread, pasta, cereal products, fruit and vegetables, milk and weekly consumption of other foods such as meat and meat products, fish, eggs, cheese, legumes. Alcoholic drinks were also investigated. This section was analyzed as frequency of food consumption [21]. 
The second section (Section B: Food Habits) consists of 14 questions. This section was aimed at investigating the food habits of the adolescents in particular related to breakfast content, number of meals a day, daily consumption of fruit and vegetables as well as of both soft and alcoholic beverages. In this section, some questions already investigated in section A were asked again aimed at evaluating if numbers of portions consumed by the subjects satisfied the ones recommended. Eight of the questions had the following response categories: always, often, sometimes, never; the other six have instead four response categories structured in different ways. This section was analyzed as frequency of consumption as well as using the score assigned to each response ranging from 0 to 3 , with the maximum score assigned to the healthiest one and the minimum score to the least healthy one. The total score of this section was 42 [21].

The third section (Section C: Physical Activity and Lifestyle) contains six questions aimed at investigating lifestyle and physical activity levels. All responses are structured in different ways according to each question, each score ranging from 0 to 3 , with the maximum score assigned to the healthiest habit. The total score of this section was 18 [21]. This section was also analyzed as frequency distribution.

The fourth section (Section D: Smoke Habits) consists of 3 questions aimed at investigating if smoking habit is present, if present, at what age adolescent smokers started and how many cigarettes a day they smoke. This section was analyzed as frequency of smoking habits.

As a measure of internal consistency of the section B and C of the questionnaire, in the validation study [20] Cronbach's alphas were computed, while Pearson's correlation was used as a measure of temporal stability. Cronbach's alpha was 0.75 for section B and 0.71 for section C indicating a good internal consistency. Pearson's correlation, used to assess test-retest reliability for both the sections, was very high, equal to 0.88 , indicating a very good temporal stability. Pearson's correlation coefficients were statistically significant with $\mathrm{p}<0.01$.

Section A, that is frequency of food consumption, is not a scale and there is no total score. Therefore temporal stability was evaluated for each item of this section. Pearson's correlation coefficients of section A items ranged from a minimum of 0.45 to a maximum of 0.90 , indicating a good temporal stability of the section A items. All Pearson correlation coefficients were statistically significant with $\mathrm{p}<0.01$. Section $\mathrm{D}$ was not formally tested.

Considering that this eating and lifestyle habits assessment will be followed by a nutrition education program designed for this specific target of adolescents, the use of this questionnaire will enable us to assess the impact of this intervention thanks to its stability when using measurements to make comparisons over time. The previous significantly good Pearson correlation coefficient results found in the validation study [20] would warrant that the observed differences in two sequential administrations will not be because of temporal instrument instability.

\section{Statistics}

Data were analysed using the SPSS for PC statistical software package version 18 (SPSS Inc., Chicago, IL, USA). The first and the fourth section answers were described by frequency distribution. The scores obtained in the other two sections were expressed as mean \pm Standard Deviation and the percentage distribution of subjects in each tertile score was calculated. Descriptive statistics were used to describe the main features of the sample. Student's T test was used to detect statistical differences between the two groups, while correlations were assessed using the Pearson's correlation coefficients. The statistical significance level was set to $\mathrm{p}<0.05$ for all tests.

\section{Results}

We analysed the clinical records of 1432 male adolescents aged 11-18 years. Using Cole's references [18], we classified the subjects on BMI values: $23.0 \%$ of subjects were overweight $(n=329), 5.4 \%$ were obese $(n=77)$ and $71.6 \%$ were normal weight $(n=1026)$. We invited all the overweight and obese subjects to participate in the study, 308 of them (75.8\%) agreed. Among all the NW who had same characteristics as for socio-economic status, physical activity and age, we randomly selected an equivalent number $(\mathrm{n}=308)$ who accepted to participate in the study. The main sports practiced by the whole sample were soccer, basketball, swimming cycling, judo and rowing. All the sample practiced 3.2 \pm 0.6 hours weekly. The overall sample characteristics are shown in Table 1 . Since the two groups were matched, no statistical differences were found between groups (OW+OB and NW) as for age and Socio Economic Status (unpaired T test $\mathrm{p}=$ N.S.). As far as Physical Activity concerns, the whole sample performed at least 4 hours per week of sports, with the NW group being more active in sports and less sedentary during leisure time. It is relevant that $58 \%$ of $\mathrm{OW}+\mathrm{OB}$ subjects has almost one component of the family who is overweight compared to $16.9 \%$ of $\mathrm{NW}$ subjects ( $<<0.01$ ). Besides adolescents $\mathrm{BMI}$ is correlated with overweight and obesity familiarity $(\mathrm{R}=0.78, \mathrm{p}<0.01)$. 


\begin{tabular}{|l|l|l|l|}
\hline Sample characteristics & NW $(\mathbf{n}=\mathbf{3 0 8})$ & OW+OB $(\mathbf{n}=\mathbf{3 0 8})$ & P value \\
\hline Average age (years) & $14.4 \pm 1.73$ & $14.2 \pm 1.83$ & N.S. \\
\hline Body Mass Index (BMI) $\mathrm{kg} / \mathrm{m}^{2}$ & $19.9 \pm 2.3$ & $27.1 \pm 4.2$ & $<0.01$ \\
\hline Presence of at least one member of the family who was overweight & $\begin{array}{l}16.9 \%^{*} \\
(52)\end{array}$ & $\begin{array}{l}58.0 \%^{*} \\
(178)\end{array}$ & $<0.01$ \\
\hline Weekly hours of sports: 4 hours & $\begin{array}{l}6.5 \%^{*} \\
(20)\end{array}$ & $\begin{array}{l}36.4 \%^{*} \\
(112)\end{array}$ & $<0.01$ \\
\hline Weekly hours of sports: $>$ 4 hours & $\begin{array}{l}93.5 \%^{*} \\
(288)\end{array}$ & $\begin{array}{l}63.6 \%^{*} \\
(196)\end{array}$ & $<0.01$ \\
\hline Spare time: sedentary activities & $\begin{array}{l}29.9 \%^{*} \\
(92)\end{array}$ & $\begin{array}{l}66.2 \%^{*} \\
(204)\end{array}$ & $<0.01$ \\
\hline Spare time: dynamic activities & $\begin{array}{l}70.1 \%^{*} \\
(216)\end{array}$ & $\begin{array}{l}33.8 \%^{*} \\
(104)\end{array}$ & $<0.01$ \\
\hline
\end{tabular}

$\mathrm{NW}=$ Normal weight subjects

$\mathrm{OW}+\mathrm{OB}=$ Overweight and obese subjects

* Percentage of subjects; in brackets number of subjects

Table 1: Overall sample characteristics

\section{Questionnaire}

\section{Section A: Frequency of Food Consumption}

No significant statistical differences were found between the two groups. The consumption of milk and yogurt was on daily base only for about $50 \%$ of the subjects in the two groups.

The intake of complex carbohydrates (such as pasta, bread, rice, potatoes) satisfied the recommendations [23]: almost 90\% of the subjects referred to eat 1-2 portions of such foods per day.

Vegetables consumption was low: only half of the sample consumed 1-2 servings per day; fruit intake was high in the two groups.

Meat consumption was higher than the recommended servings, being "almost every day" for about $50 \%$ of the groups. Whereas, fish intake was low: only about half of the subjects in the two groups consumed it at least once per week.

Cheese, ham, salami and sausages consumption was similar into the two groups; in particular, they were consumed almost every day by $60 \%$ of the subjects.

Eggs were generally consumed about 2 to 3 times a week and the consumption of legumes was mainly reported as "sometimes".

Sweets and cakes were part of the daily diet for about one third of the whole sample.

French fries intake was reported as "almost every day" by $39.0 \%$ and $23.0 \%$ of OW+OB and NW subjects respectively.

Alcohol consumption was similar in the two groups, about $20.0 \%$ of the subjects; only the oldest ones (>14 years of age) usually drank 1 glass of beer or wine or other alcoholic drinks once a week, in both groups.

\section{Section B: Food Habits}

No significant statistical differences were found between the two groups.

About 30\% of both groups skipped breakfast every day. If consumed, breakfast was mainly based on milk and cereals. Only $23.4 \%$ of the OW+OB group and $27.3 \%$ of the NW subjects consumed two portions of fruit every day. As for vegetables, only $18.2 \%$ of the $\mathrm{OW}+\mathrm{OB}$ group and $42.8 \%$ of the NW one consumed them daily, at least 2 times a day. More than $40 \%$ of the subjects did not drink enough water throughout the day. High sugar soft drinks consumption was extremely high, more than the $50.0 \%$ of both groups consumed such drinks every day. Most of the subjects were able to correctly share out the energy intake during the day. The mean score obtained was $22 \pm 3$ and $24 \pm 4$ for the OW+OB group and the NW one respectively (p=NS).

In Table 2 percentage of distribution of subjects according to tertile scores is reported for NW and OW+OB subjects respectively.

\begin{tabular}{|l|l|l|l|l|l|l|}
\hline \multicolumn{1}{|c|}{ Questionnaire sections } & \multicolumn{3}{c|}{ NW Subjects (n 308) } & \multicolumn{3}{c|}{ OW+OB subjects (n 308) } \\
\hline & $1^{\text {st }}$ tertile & $2^{\text {nd }}$ tertile & $3^{\text {rd }}$ tertile & $1^{\text {st }}$ tertile & $2^{\text {nd }}$ tertile \\
\hline B. Eating habits & 19.5 & 52.3 & 28.2 & 20.3 & 53.8 \\
\hline C. Physical activity and lifestyle & 5.1 & 43.6 & 50.3 & 60.7 & 25.9 \\
\hline
\end{tabular}

NW=Normal Weight

$\mathrm{OW}+\mathrm{OB}=$ Overweight + Obese

Table 2: Percentage distribution of subjects according to Tertile Scores (\%) 


\section{Section C: Physical Activity and Lifestyle}

All the sample used to practice sport during the entire year, 93.5\% and 63.6\% of NW adolescents and OW+OB subjects respectively practice physical activity more than 4 hours a week $(\mathrm{p}<0.01)$. About $75 \%$ of NW prefer dynamic activities during the spare time while most of $\mathrm{OW}+\mathrm{OB}$ adolescents $(66.2 \%)$ would rather choose sedentary activities such as watching TV, listening to music and using the computer. A statistically significant difference was found between NW and OW+OB group with the highest score obtained by the NW subjects ( $14 \pm 2$ vs $8 \pm 3 ; \mathrm{p}<0.001)$.

In Table 2 percentage of distribution of subjects according to tertile scores is reported for NW and OW+OB subjects respectively. Analysing the overall sample, we found a statistically significant negative correlation between weight and weekly amount of physical activity hours $(\mathrm{R}=0.78, \mathrm{p}=0.01)$.

Another statistically significant correlation was found between personal preferences of activity during spare time and weight: subjects who prefer dynamic activities had a lower weight $(\mathrm{R}=0.76, \mathrm{p}<0.001)$.

\section{Section D: Smoking Habits}

The percentage of the subjects who smoke (about 14\%) is really similar within the groups (p=N.S.) (Table 3). Most adolescent smokers refer to start after 13 years of age and most of them smoke less than 10 cigarettes a day. We found a statistically significant positive correlation between smoking habit and alcohol intake $(\mathrm{p}=0.000 ; \mathrm{R}=0.82)$.

\begin{tabular}{|c|c|c|c|c|c|}
\hline Questions & Answers & $\mathrm{n}(\mathrm{OW}+\mathrm{OB})$ & n (NW) & $\%(\mathrm{OW}+\mathrm{OB})$ & $\%(\mathrm{NW})$ \\
\hline 1. Do you smoke? & $\begin{array}{l}\bullet \text { yes } \\
\text { - no }\end{array}$ & $\begin{array}{l}48 \\
260\end{array}$ & $\begin{array}{l}43 \\
265\end{array}$ & $\begin{array}{l}15.5 \\
84.5\end{array}$ & $\begin{array}{l}13.9 \\
86.1\end{array}$ \\
\hline 2. If yes, when did you start? & $\begin{array}{l}\bullet 11-13 \text { years old } \\
\bullet 14-16 \text { years old } \\
\bullet 17-18 \text { years old }\end{array}$ & $\begin{array}{l}13 \\
19 \\
16\end{array}$ & $\begin{array}{l}12 \\
17 \\
14\end{array}$ & $\begin{array}{l}28.1 \\
38.1 \\
33.8\end{array}$ & $\begin{array}{l}28.1 \\
39.4 \\
32.5\end{array}$ \\
\hline 3.How many cigarettes do you smoke? & $\begin{array}{l}\text { - Less than } 5 \text { cigarettes a day } \\
\text { - } 5 \text { - } 10 \text { cigarettes a day } \\
\text { - More than } 10 \text { cigarettes a day }\end{array}$ & $\begin{array}{l}17 \\
16 \\
15\end{array}$ & $\begin{array}{l}15 \\
15 \\
13\end{array}$ & $\begin{array}{l}36.4 \\
33.1 \\
30.5\end{array}$ & $\begin{array}{l}35.7 \\
34.3 \\
30.0\end{array}$ \\
\hline
\end{tabular}

Table 3: Section D results: Smoking Habits

\section{Discussion}

This study was conducted on 11-18 years old, male children and adolescents clinical records who underwent a medical evaluation in a Sports Medical Centre.

We recruited $308 \mathrm{OW}+\mathrm{OB}$ subjects and, within the group of NW adolescents, we randomly included an equivalent number of adolescents who had same characteristics as for socio-economic status, physical activity and age. Hence, we handed and explained the validated self-administered life style questionnaire aimed at outlining the main characteristics of the current lifestyle and dietary pattern of physically active male adolescents, comparing them for BMI.

The prevalence of OW+OB (28.4\%) in our sample of "physical active adolescents" (n 1432) was equivalent to that observed in the male Italian adolescent population aged 11-15 years in 2010 [24] who typically perform three hours of physical activity per week (less than $50 \%$ of males and less than $30 \%$ of females).

From our results it is clear that both $\mathrm{OW}+\mathrm{OB}$ as well as NW teenagers have unhealthy food habits with no statistically significant difference between the two groups, despite physical activity that should promote healthy eating habits for a better performance, involving them in a "healthier" environment as far as lifestyle is concerned.

Nevertheless, the consumption of vegetables did not meet the recommendations in the overall sample, however, the proportion of subjects meeting the recommended number of daily vegetable servings was significantly higher in the NW group compared to the $\mathrm{OW}+\mathrm{OB}$ (42.8\% vs $18.2 \%)$.

These data seem to support those reported by literature which demonstrate that among boys vegetable intake was inversely related to BMI z-score changes, attenuated after control for caloric intake [25].

According to our investigation, the adolescents diet was characterized mostly by food rich in saturated fats and salt (meat, eggs, salami, ham and prosciutto), nevertheless $50 \%$ of the subjects referred to consume fish at least once per week. The consumption of milk and yoghurt did not reach the recommendations as well as the vegetables intake resulting in a diet poor in calcium, fibre and micronutrients. We found a high number of breakfast skippers, about $30 \%$ of the whole sample did not consume breakfast daily. Literature demonstrated a strong correlation between overweight and breakfast skipping; in particular a recent study found an association between high blood glucose and lipid levels and skipping meals, mainly breakfast, in obese children and adolescents [26]. 
The soft drinks intake of the whole sample was high both in the NW group as well as in the OW+OB one. It is important to underline that soft drinks are sugary beverages that, apart from sugar, energy and fluid, do not provide other nutritional value. A high consumption of such beverages has been associated with obesity, metabolic syndrome, type 2 diabetes [27-29], dental caries [30] and low bone mineral density [31,32].

Recently research interest is drawn towards the possible link between salt and soft drinks consumption. We have not calculated the salt intake of our sample, however processed meats such as ham, salami and sausages are eaten every day by over $60 \%$ of the adolescents, regardless of BMI.

In a study by He FJ et al. [33] it is suggested that, since soft drinks consumption is an important total fluid intake component in children, a reduction in salt intake could not only have a beneficial effect on blood pressure but also be the way to reduce these drinks intake. This would lead to cardiovascular disease prevention and childhood obesity reduction respectively.

As for alcohol consumption and smoking habit, we found lower percentages of subjects compared to the national data [34,35], we can hypothesize that sport practice acts as a protective factor towards unhealthy habits. Since we did not find any consistent difference between the two groups regarding food habits, we analysed the physical activity besides the time dedicated to sports.

We found a statistically significant negative correlation between hours of physical activity and BMI. Normal weight subjects who practice sports more than 4 hours a week are almost 30\% more than $\mathrm{OW}+\mathrm{OB}(93.5 \%$ vs $63.6 \%)$.

Moreover, about $70 \%$ of NW prefers dynamic activities during the spare time whereas the majority of OW+OB adolescents (66.2\%) would rather choose sedentary activities such as watching TV, listening to music, using the computer, playing videogames.

In agreement with our data, physical inactivity and sedentarism [36] are important factors in promoting and maintaining overweight.

Recently, achieving 10,000 steps per day has received scientific approval [37-39] as an index for minimum level of physical activity to achieve energy balance.

However time spent sleeping, eating, standing still, sitting, viewing television, playing games or working on a computer, talking on a phone, riding in a train, plane, car or driving should be taken into account. The prevalence of screen time (TV, computer, screen games) has been studied and has been identified as the greatest single contributing factor to sedentarism [40].

A recent study suggests that reduction of time spent watching TV may be an effective strategy to prevent excess weight gain among adolescents [41]. However it is difficult to say if this sedentarism is the cause of overweight or a consequence maintaining overweight itself [42].

Undoubtedly obesity is a social disease and being overweight means not being competitive with the other peers. So, not engaging in dynamic activities during the spare time may be a consequence of the exclusion due to overweight condition.

An important data we cannot ignore is the family history. Many studies are focusing on parenting styles [43-45] and it is relevant that $58 \%$ of $\mathrm{OW}+\mathrm{OB}$ subjects in our sample has almost one component of the family who is overweight. This is also a known confounder [46] and is correlated with BMI in our sample $(\mathrm{R}=0.78, \mathrm{p}<0.01)$. In order to define an efficient area of intervention, the family lifestyle should be always seriously considered. Since many variables are consistently associated with adolescents' physical activity [46] statistics demonstrated that there is no difference between both groups in a number of key characteristics that can effect lifestyle behaviours such as sex, ethnicity, age, previous physical activity, school sports ( $\mathrm{p}=$ N.S.).

It is relevant to underline that the sample may have learned about the importance of consuming vegetables and not drinking alcoholic beverages elsewhere. It should be interesting to further investigate the social desirability that may tend to overestimate healthy eating habits as well as PA.

Additionally the self-report instruments for capturing physical activity and dietary behaviours in adolescents have some limitations as reported in literature [47-49].

Nevertheless the use of a large number of subjects, as in our study, commonly reduces problems [48]. Despite the problems outlined in literature, self-administered questionnaires have practical value in indicating conditions where an improve in lifestyle habits would be beneficial as well as in monitoring changes [48].

\section{Conclusions}

Effective strategies may focus on determinants of healthful and sustainable behavior patterns, rather than focus on any single aspect (i.e. food habits, physical activity or sedentarism) both for $\mathrm{OW}+\mathrm{OB}$ as well as $\mathrm{NW}$ adolescents.

According to our present analysis the physical activity and sports practice alone do not lead to a healthier eating habits, nor lower overweight and obesity prevalence in male adolescents.

Public health interventions should focus on nutrition and behavioral education programs besides the reinforcement of leisure time physical activity, in order to prevent obesity in the adulthood.

\section{Click here to download Appendix File}




\section{References}

1. Han JC, Lawlor DA, Kimm SY (2010) Childhood obesity. Lancet 375: 1737-48.

2. Bessesen DH (2008) Update on obesity. J Clin Endocrinol Metab 93: 2027-34.

3. Whitaker RC, Wright JA, Pepe MS, Seidel KD, Dietz WH (1997) Predicting obesity in young adulthood from childhood and parental obesity. N Engl J Med 337: 869-73.

4. Scaglioni S, Salvioni M, Galimberti C (2008) Influence of parental attitudes in the development of children eating behaviour. Br J Nutr 99: 22-5.

5. WHO (2009) The European health report. Health and health systems, Geneva.

6. Hoglund D, Samuelson G, Mark A (1998) Food habits in Swedish adolescents in relation to socioeconomic conditions. Eur J Clin Nutr 52: 784-9.

7. Alexy U, Sichert-Hellert W, Kersting M (2002) Fifteen-year time trends in energy and macronutrient intake in German children and adolescents: results of the DONALD study. Br J Nutr 87: 595-604.

8. Lambert J, Agostoni C, Elmadfa I, Hulshof K, Krause E, et al.(2004) Dietary intake and nutritional status of children and adolescents in Europe. Br J Nutr 92: 147-211.

9. Malik VS, Schulze MB, Hu FB (2006) Intake of sugar-sweetened beverages and weight gain: a systematic review. Am J Clin Nutr 84: 274-88.

10. Drewnowski A, Bellisle F (2007) Liquid calories, sugar and body weight. Am J Clin Nutr 85: 651-61.

11. Vartanian LR, Schwartz MB, Brownell KD (2007) Effects of soft drink consumption on nutrition and health: a systematic review and meta-analysis. Am J Public Health 97: 667-75.

12. Currie C (2004) Health Behaviour in School-aged Children (HBSC) study: international report from the 2001/2002 survey: WHO Library. Geneva, Switzerland.

13. Davison KK, Birch LL (2001) Childhood overweight: a contextual model and recommendations for future research. Obes Rev 2: 159-71.

14. Cecchini M, Sassi F, Lauer JA, Lee YY, Guajardo-Barron V, et al. (2010) Tackling of unhealthy diets, physical inactivity, and obesity: health effects and costeffectiveness. Lancet 376: 1775-84.

15. Eheman C, Henley SJ, Ballard-Barbash R, Jacobs EJ, Schymura MJ, et al. (2012) Annual Report to the Nation on the status of cancer, 1975-2008, featuring cancers associated with excess weight and lack of sufficient physical activity. Cancer 118: 2338-66.

16. Ziemba AW, Chwalbińska-Moneta J, Kaciuba-Uścilko H, Kruk B, Krzeminski K, et al. (2003) Early effects of short-term aerobic training. Physiological responses to graded exercise. J Sports Med Phys Fitness 43: 57-63.

17. Bleich SN, Ku R, Wang YC (2011) Relative contribution of energy intake and energy expenditure to childhood obesity: a review of the literature and directions for future research. Int J Obes (Lond) 35: 1-15.

18. Olshansky SJ, Passaro DJ, Hershow RC, Layden J, Carnes BA, et al. (2005) A potential decline in life expectancy in the United States in the 21st century. N Engl J Med, 352: 1138-45.

19. Cole TJ, Lobstein T (2012) Extended international (IOTF) body mass index cut-offs for thinness, overweight and obesity. Pediatr Obes 7: $284-94$.

20. Turconi G, Celsa M, Rezzani C, Biino G, Sartirana MA, et al. (2003) Reliability of a dietary questionnaire on food habits, eating behaviour and nutritional knowledge of adolescents. Eur J Clin Nutr 57: 753-63.

21. Turconi G, Guarcello M, Maccarini L, Cignoli F, Setti S, et al. (2008) Eating habits and behaviors, physical activity, nutritional and food safety knowledge and beliefs in an adolescent Italian population. J Am Coll Nutr 27: 31-43.

22. Cole TJ, Lobstein T (2012) Extended international (IOTF) body mass index cut-offs for thinness, overweight and obesity. Pediatr Obes 7: 284-94.

23. INRAN (2003) Linee Guida per una sana alimentazione italiani.

24. Ministero della Salute, Ministero dell'Istruzione (2010) Studio HBSC Italia 2010 (Health Behaviour in School-aged Children), Rome, Italy.

25. Field AE, Gillman MW, Rosner B, Rockett HR, Colditz GA (2003) Association between fruit and vegetable intake and change in body mass index among a large sample of children and adolescents in the United States. Int J Obes Relat Metab Disord 27: 821-6.

26. Freitas Júnior IF, Christofaro DG, Codogno JS, Monteiro PA, Silveira LS, et al. (2012) The association between skipping breakfast and biochemical variables in sedentary obese children and adolescents. J Pediatr 161: 871-4.

27. Hu FB, Malik VS (2010) Sugar-sweetened beverages and risk of obesity and type 2 diabetes: epidemiologic evidence. Physiol Behav 100: 47-54.

28. Malik VS, Popkin BM, Bray GA, Després JP, Hu FB (2010) Sugar-sweetened beverages, obesity, type 2 diabetes mellitus, and cardiovascular disease risk. Circulation 121: 1356-64.

29. Malik VS, Popkin BM, Bray GA, Després JP, Willett WC, et al. (2010) Sugar-sweetened beverages and risk of metabolic syndrome and type 2 diabetes: a metaanalysis. Diabetes Care 33: 2477-83.

30. Cheng R, Yang H, Shao MY, Hu T, Zhou XD (2009) Dental erosion and severe tooth decay related to soft drinks: a case report and literature review. J Zhejiang Univ Sci B 10: 395-9.

31. Hostmark AT, Søgaard AJ, Alvær K, Meyer HE (2011) The oslo health study: a dietary index estimating frequent intake of soft drinks and rare intake of fruit and vegetables is negatively associated with bone mineral density. J Osteoporos: 102686.

32. Libuda L, Alexy U, Remer T, Stehle P, Schoenau E, et al. (2008) Association between long-term consumption of soft drinks and variables of bone modeling and remodeling in a sample of healthy German children and adolescents. Am J Clin Nutr 88: 1670-7.

33. He FJ, Marrero NM, MacGregor GA (2008) Salt intake is related to soft drink consumption in children and adolescents: a link to obesity? Hypertension 51: 629-34.

34. Leclercq C, Arcella D, Piccinelli R, Sette S, Le Donne C, et al. (2009) The Italian National Food Consumption Survey- INRAN- SCAI 2005-2006: main Results in terms of food consumption. Pub Health Nutr 12: 2504-32.

35. The portal of epidemiology to public health: The data on smoking. National Centre for Epidemiology, Surveillance and Health Promotion.

36. Ricciardi R (2005) Sedentarism: a concept analysis. Nurs Forum 40: 79-87.

37. Dunn AL, Marcus BH, Kampert JB, Garcia ME, Kohl HW, et al. (1999) Comparison of lifestyle and structured interventions to increase physical activity and cardiorespiratory fitness: a randomized trial. JAMA 281: 327-34.

38. Hill JO, Wyatt HR, Reed GW, Peters JC (2003) Obesity and the environment: where do we go from here? Science 299: 853-5.

39. Rowlands AV, Eston RG (2005) Comparison of accelerometer and pedometer measures of physical activity in boys and girls, ages 8-10 years. Res Q Exerc Sport 76: 251-7.

40. Boone JE, Gordon-Larsen P, Adair LS, Popkin BM (2007) Screen time and physical activity during adolescence: longitudinal effects on obesity in young adulthood. Int J Behav Nutr Phys Act 4: 26. 
41. French SA, Mitchell NR, Hannan PJ (2012) Decrease in television viewing predicts lower body mass index at 1-year follow-up in adolescents, but not adults. J Nutr Educ Behav 44: 415-22.

42. Metcalf BS, Hosking J, Jeffery AN, Voss LD, Henley W, et al. (2011) Fatness leads to inactivity, but inactivity does not lead to fatness: a longitudinal study in children (EarlyBird 45). Arch Dis Child 96: 942-7.

43. Faith MS, Van Horn L, Appel LJ, Burke LE, Carson JA, et al. (2012) Evaluating parents and adult caregivers as "agents of change" for treating obese children: evidence for parent behavior change strategies and research gaps: a scientific statement from the American Heart Association. Circulation 125: $1186-207$.

44. Birch LL, Davison KK (2001) Family environmental factors influencing the developing behavioral controls of food intake and childhood overweight. Pediatr Clin North Am 48: 893-907.

45. Golan M, Crow S (2004) Targeting parents exclusively in the treatment of childhood obesity: long-term results. Obes Res 12: 357-61.

46. Sallis JF, Prochaska JJ, Taylor W C. (2000) A review of correlates of physical activity of children and adolescents. Med Sci Sports Exerc 32: $963-75$.

47. Trost SG (2007) State of the Art Reviews: Measurement of Physical Activity in Children and Adolescents. American journal of Lifestyle Medicine 4: 299-314.

48. Shephard RJ (2003) Limits to the measurement of habitual physical activity by questionnaires. Br J Sports Med 37: 197-206.

49. Brener ND, Billy J, Grady WR (2003) Assessment of factors affecting the validity of self-reported health-risk behavior among adolescents: evidence from the scientific literature. J Adolesc Health 33: 436-57.

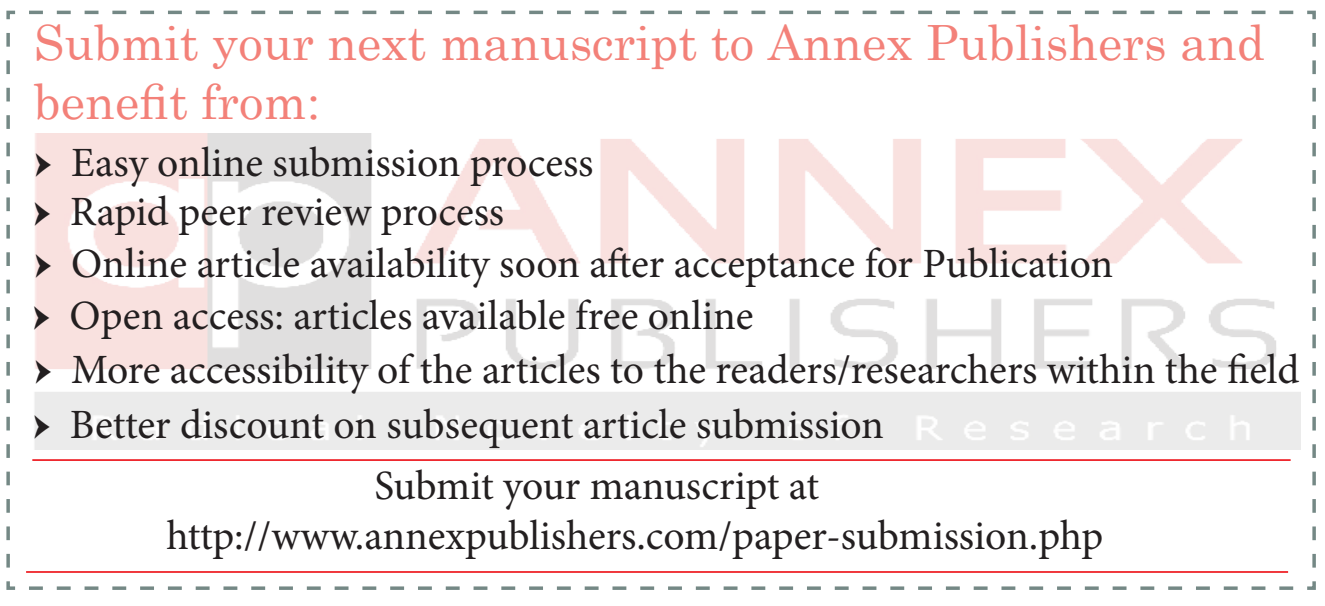

